\title{
The Roles of the Gut Microbiota and Chronic Low-Grade Inflammation in Older Adults With Frailty
}

\author{
YuShuang $\mathrm{Xu}^{1,2}$, XiangJie Liu ${ }^{3}$, XiaoXia Liu ${ }^{3}$, Di Chen ${ }^{1,2}$, MengMeng Wang ${ }^{1,2}$, \\ Xin Jiang ${ }^{1,2}$ and ZhiFan Xiong ${ }^{1,2 *}$
}

\section{OPEN ACCESS}

Edited by:

Francesca Romana Ponziani, Internal Medicine, Gastroenterology, Hepatology Fondazione Policlinico

Universitario Agostino Gemell (IRCCS), Italy

Reviewed by: Yiorgos Apidianakis, University of Cyprus, Cyprus Simone Garcovich, Catholic University of the Sacred Heart, Italy

*Correspondence: ZhiFan Xiong xiongzhifan@126.com

Specialty section: This article was submitted to Microbiome in Health and Disease, a section of the journal

Frontiers in Cellular and Infection Microbiology

Received: 04 March 2021 Accepted: 14 June 2021 Published: 01 July 2021

Citation:

Xu Y, LiU X, LiU X, Chen $D$, Wang $M$, Jiang $X$ and Xiong Z (2021) The Roles of the Gut Microbiota and Chronic

Low-Grade Inflammation in

Older Adults With Frailty. Front. Cell. Infect. Microbiol. 11:675414. doi: 10.3389/fcimb.2021.675414

\begin{abstract}
${ }_{1}^{1}$ Division of Gastroenterology, Liyuan Hospital, Tongji Medical College, Huazhong University of Science and Technology, Wuhan, China, ${ }^{2}$ Institute of Geriatric Medicine, Liyuan Hospital, Tongji Medical College, Huazhong University of Science and Technology, Wuhan, China, ${ }^{3}$ Division of Geriatric, Liyuan Hospital, Tongji Medical College, Huazhong University of Science and Technology, Wuhan, China
\end{abstract}

Frailty is a major public issue that affects the physical health and quality of life of older adults, especially as the population ages. Chronic low-grade inflammation has been speculated to accelerate the aging process as well as the development of age-related diseases such as frailty. Intestinal homeostasis plays a crucial role in healthy aging. The interaction between the microbiome and the host regulates the inflammatory response. Emerging evidence indicates that in older adults with frailty, the diversity and composition structure of gut microbiota are altered. Age-associated changes in gut microbiota composition and in their metabolites contribute to increased gut permeability and imbalances in immune function. In this review, we aim to: identify gut microbiota changes in the aging and frail populations; summarize the role of chronic low-grade inflammation in the development of frailty; and outline how gut microbiota may be related to the pathogenesis of frailty, more specifically, in the regulation of gut-derived chronic inflammation. Although additional research is needed, the regulation of gut microbiota may represent a safe, easy, and inexpensive intervention to counteract the chronic inflammation leading to frailty.

Keywords: gut microbiota, chronic low-grade inflammation, aging, frailty, review

\section{INTRODUCTION}

Frailty is a clinical syndrome characterized by "diminished strength, endurance, and reduced physiological function". Frailty predisposes patients to negative health-related outcomes such as falls, hospitalization, disability, dependency, and mortality (Hirani et al., 2015; Wilson et al., 2017; Picca et al., 2019). The prevalence of frailty ranges from $4 \%$ to $59 \%$ in community-dwelling older 
adults and increases with age (Collard et al., 2012). Given the rapidly aging population, the United Nations estimates that worldwide, the number of people aged 60 years and above will double to nearly 2.1 billion by 2050 (Jayanama and Theou, 2019). Therefore, frailty is a pressing concern in aging societies (Morley et al., 2013).

Aging is an irreversible, complex biological process determined by a combination of genetic, epigenetic, and environmental factors (O'Toole and Jeffery, 2015; Melzer et al., 2020). Microorganisms, as an environmental factor, are among the most interesting contributors to aging, and they provide a new perspective in understanding the aging process (Finlay et al., 2019). As a person ages, progressive changes in intestinal tract physiology, the intestinal mucosal immune system, lifestyle changes (particularly in diet and exercise), medication, malnutrition, inflammation, and immune senescence may change the diversity, composition and functional features of the gut microbiota (Li et al., 2016; Adriansjach et al., 2020; DeJong et al., 2020). Data from animal models demonstrate that age-related microbial dysbiosis contributes to intestinal permeability, systemic inflammation, and premature mortality (DeJong et al., 2020). Though the cause-and-effect relationship is unclear, age-related microbial dysbiosis is linked to unhealthy aging and geriatric syndromes, which include frailty. Identifying specific changes in frailty-related gut microbiota is essential in developing microbiome-based diagnostic and therapeutic strategies.

In this review, we first describe the relevant changes in gut microbiota related to aging and frailty. Subsequently, we summarize recent findings on the possible role of chronic low-grade inflammation in frailty and how microbial dysbiosis is involved in its pathogenesis, including frailty-related inflammation.

\section{THE DEFINITIONS AND INFLAMMATORY BIOMARKERS OF FRAILTY}

The concept of frailty was formally put forward in the 1970 s and since then has continuously evolved (Rockwood K et al., 1994). Frailty is not the result of a singular disease-it often follows from a series of chronic diseases, an acute event, or a serious disease. Frailty usually involves physical and psychosocial factors, which can be subdivided into physical frailty, cognitive frailty, and psychosocial frailty (Malmstrom TK, 2013).

The definition of physical frailty is widely recognized; it manifests as a decrease in physical strength and physiological reserve, and minor external stimuli can cause clinical events. The frailty phenotype (FP) and frailty index (FI) are two leading assessment criteria used to identify physical frailty. According to Fried's FP, of the five clinical symptoms (unintentional weight loss, loss in grip strength, self-reported exhaustion, slow walking speed, and low physical activity), individuals with three are considered frail, and those with one or two are identified as pre-frail (Cesari et al., 2014). In contrast, the FI is a dynamic, continuous process that involves the accumulation of deficits, and as these deficits increase, frailty increases. The FI may be useful in assessing the effectiveness of interventions as well as tracking any changes or trends in a patient's health situation (Cesari et al., 2014).

Cognitive frailty is a subtype of frailty (Ruan et al., 2015). It refers to the coexistence of physical frailty and reduced cognitive reserves, which include mild cognitive impairment (MCI) (i.e., Clinical Dementia Rating score equal to 0.5) but not dementia (Ticinesi et al., 2018). Cognitive frailty is considered to be a form of pathological brain aging and is an early sign of neurodegeneration (Ruan et al., 2015). The characteristics of cognitive impairment, such as deterioration of executive function and attention, are related to weak grip strength and slow walking speed (Robertson et al., 2014). In the aging process, cognitive and physical frailty interact and increase the risk of poor prognosis (Robertson et al., 2013). At present, no unified assessment tool for cognitive frailty exists. Instead, assessments of physical frailty are often combined with cognitive function assessment scales to screen older adults with cognitive frailty.

As proposed by Franceschi et al. in 2000, "inflamm-aging" is an age-associated proinflammatory status and consists of the reduced capacity to cope with various stressors (Franceschi C and Valensin, 2000). Although its causal relationship is still unclear, the relevance of systemic inflammation to the pathophysiology of frailty has been reported in many papers. The potential inflammatory biomarkers of older adults with frailty are summarized in Table $\mathbf{1}$.

White blood cells (WBC), lymphocytes, C-reactive protein (CRP), interleukin (IL)-6, IL-10, and tumor necrosis factor alpha (TNF- $\alpha$ ) are inflammatory biomarkers that have gained attention in the past decade (Qu et al., 2009; Fontana et al., 2013; Soysal et al., 2016; Marcos-Perez et al., 2018; Nascimento et al., 2018; Rusanova et al., 2018; Yang et al., 2018; NavarroMartinez et al., 2019; Hsu et al., 2019; Furtado et al., 2020; Castellana et al., 2021). A meta-analysis from 2016 concluded that older adults with frailty and pre-frailty had significantly higher levels of CRP, TNF- $\alpha$, IL-6, white blood cells, and fibrinogen (Soysal et al., 2016). However, this conclusion was mainly based off of cross-sectional studies; not enough highquality longitudinal data were available for consistent conclusions to be drawn. Lymphocytes are significantly positively correlated with both physical activity and hand grip strength. Grip strength refers to the maximum grip strength of the dominant hand; it is used as a single marker of frailty in similarly aged people (Fernández-Garrido et al., 2014). IL-10 is a controversial biomarker, with part of the study revealing high serum concentrations of IL-10 in frail groups (Rusanova et al., 2018; Furtado et al., 2020). But differs from the frail humans, the genetically altered IL-10 tm/tm mouse, which lacks IL-10 expression, is more sensitive to the activation of inflammatory pathways (Walston and Yang, 2008).

Hus et al. suggested that frailty may not be a nonspecific paninflammatory condition and is cross-sectionally associated with 
TABLE 1 | Potential inflammatory biomarkers of older adults with frailty.

\begin{tabular}{|c|c|c|c|c|c|}
\hline Biomarker & Nature & Diagnostic criteria & Setting & Regulation in frailty & Reference \\
\hline WBC & Blood cell & FP & Community & Up-regulated & $\begin{array}{l}\text { Castellana et al. (2021) } \\
\text { Fontana et al. (2013) }\end{array}$ \\
\hline Lymphocytes & Blood cell & FP & Hospital & Down-regulated & $\begin{array}{l}\text { Navarro-Martinez et al. (2019) } \\
\text { Fontana et al. (2013) }\end{array}$ \\
\hline CRP & Protein & FP & Hospital, Community & Up-regulated & $\begin{array}{l}\text { Navarro-Martinez et al. (2019) } \\
\text { Marcos-Perez et al. (2018) } \\
\text { Fontana et al. (2013) } \\
\text { Yang et al. (2018) }\end{array}$ \\
\hline PCT & Protein & $\mathrm{FP}$ & Hospital & Up-regulated & Yang et al. (2018) \\
\hline$\|-1 \alpha$ & Cytokine & $\mathrm{FP}$ & Community & Up-regulated & Nascimento et al. (2018) \\
\hline IL-6 & Cytokine & $\mathrm{FP}, \mathrm{FI}$ & Community & Up-regulated & $\begin{array}{l}\text { Castellana et al. (2021) } \\
\text { Navarro-Martinez et al. (2019) } \\
\text { Marcos-Perez et al. (2018) } \\
\text { Nascimento et al. (2018) } \\
\text { Hsu et al. (2019) } \\
\text { Qu et al. (2009) } \\
\text { Yang et al. (2018) } \\
\text { Rusanova et al. (2018) }\end{array}$ \\
\hline IL-8 & Cytokine & $\mathrm{FP}, \mathrm{FI}$ & Hospital, Community & Up-regulated & $\begin{array}{l}\text { Navarro-Martinez et al. (2019) } \\
\text { Hsu et al. (2019) } \\
\text { Rusanova et al. (2018) }\end{array}$ \\
\hline $\mathrm{IL}-10$ & Cytokine & FP & Community & Up-regulated & $\begin{array}{l}\text { Furtado et al. (2020) } \\
\text { Rusanova et al. (2018) }\end{array}$ \\
\hline $\mathrm{TNF}-\alpha$ & Cytokine & FP & Community, Hospital & Up-regulated or Down-regulated & $\begin{array}{l}\text { Castellana et al. (2021) } \\
\text { Furtado et al. (2020) } \\
\text { Navarro-Martinez et al. (2019) } \\
\text { Marcos-Perez et al. (2018) } \\
\text { Nascimento et al. (2018) } \\
\text { Rusanova et al. (2018) }\end{array}$ \\
\hline CXCL10 & Chemokine & $\mathrm{FP}$ & Community & Up-regulated & Qu et al. (2009) \\
\hline MCP-1 & Chemokine & FP & Community & Up-regulated & Lu et al. (2016) \\
\hline RANTES & Chemokine & FP & Community & Up-regulated & Lu et al. (2016) \\
\hline ICAM-1 & Protein & FP & Community & Up-regulated & Lee et al. (2016) \\
\hline sRAGE & Protein & FP & Community & Up-regulated & Butcher et al. (2019) \\
\hline
\end{tabular}

WBC, White blood cells; PCT, Procalcitonin; IL, Interleukin; TNF- $\alpha$, Tumor necrosis factor alpha; CXCL10, Chemokine (C-X-C motif) ligand10; FP, Fraity phenotype; FI, Frailty index; MCP-1,

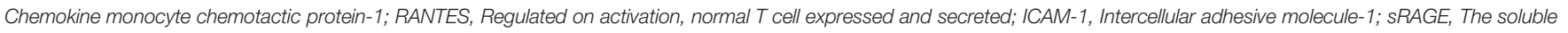
receptor for advanced glycation end-products.

IL-6 and IL-8 (Hsu et al., 2019). IL-1 $\alpha$ plasmatic levels in prefrail subjects are significantly higher than non-frail ones (Nascimento et al., 2018). Yang et al. reported that procalcitonin (PCT) is associated with frailty in a non-infected group rather than the pneumonia group (Yang et al., 2018). (C-X-C motif) ligand (CXCL)10 (CXCL10) is a potent proinflammatory chemokine that is increased in frail participants. In turn, frailty-associated CXCL10 upregulation is related to elevated serum IL-6 levels ( $\mathrm{Qu}$ et al., 2009). Similar to the changes observed during aging, chemokine monocyte chemotactic protein-1 (MCP-1) and regulated on activation, normal $\mathrm{T}$ cell expressed and secreted (RANTES) are positively associated with frailty (Lu and Nyunt, 2016). Lee et al. observed higher levels of intercellular adhesive molecule-1 (ICAM-1) in frail older adults and consequently proposed that leukocyte migration and inflammation cascade activation may be involved in the development of frailty (Lee et al., 2016). Finally, soluble receptor for advanced glycation end-products (sRAGE) is associated with a higher risk of death among frail subjects (Butcher et al., 2019).

\section{ALTERATIONS OF THE GUT MICROBIOTA IN AGING AND FRAILTY}

\section{Aging-Related Changes in the Gut Microbiota}

Changes in the gut microbiota are closely related to the aging process and its related disease outcomes (Bana and Cabreiro, 2019). Compared to younger adults, the gut microbiota composition in older adults is less diverse, and the interindividual variation is greater (Claesson et al., 2012; Bischoff, 2016). This larger variation may be related to external factors that influence the gut microbiota such as diet, exercise, or medication (O'Toole and Jeffery, 2015). Claesson et al. analyzed the fecal microbiota of 161 older adults (aged over 65 ) and 9 younger controls. They found a greater proportion of Bacteroides spp. and distinct abundance patterns of Clostridium groups in the fecal microbiota of older adults. The proportions of some disease- or health-related phyla and genera such as Proteobacteria, Actinobacteria, and Faecalibacteria also varied dramatically among the individuals (Claesson et al., 20111). 
Notably, another study reported that in the same population, the gut microbiota composition of healthy older adults and healthy young participants were similar (Bian et al., 2017). Accordingly, "healthy and younger" gut microbiota may be beneficial for healthy aging.

Longevity is a complex process that involves longer life expectancies and a slower pace of aging. The gut microbiota of Sardinian centenarians display decreases in Faecalibacterium prausnitzii and Eubacterium rectale and increases in Methanobrevibacter smithii and Bifidobacterium adolescentis (Wu L et al., 2019). Notably, decreases in F. prauznitzii were reported by Biag et al. to have anti-inflammatory properties. They also found that Eubacterium citrate and their relatives, considered to be signature bacteria of a longer life, were increased approximately 15-fold in centenarians (Biagi et al., 2010). Moreover, the gut microbiota of centenarians (aged 99-104 years) and semi-supercentenarians (aged 105-109 years) demonstrated an increased abundance of species from Akkermansia, Bifidobacterium, and Christensenellaceae (Biagi et al., 2016).

Although the community compositions and structures of gut microbiota differ between Chinese and Italian centenarians, they do exhibit some common features that are different from younger people. For example, the alpha diversity of the gut microbiota is increased in the long-living group, and Clostridium cluster XIVa, Ruminococcaceae, Akkermansia and Christensenellaceae are enriched (Kong et al., 2019). Clostridium cluster XIVa and Ruminococcaceae are genera that contain butyrate-producing bacteria. Butyrate is an most important energy source of colon epithelial cells and has antiinflammatory properties (Liu et al., 2018). Akkermansia muciniphila is a promising probiotic and is associated with host metabolic functions and immune responses (Dao et al., 2016; Zhang et al., 2019). Finally, the human gut bacteria Christensenellaceae is negatively correlated with metabolic disorders and inflammation-related diseases such as inflammatory bowel disease (Waters and Ley, 2019).

\section{The Gut Microbiota and Frailty}

We summarized available articles regarding the relationship between changes in the gut microbiota and frailty in the older adult population. The results are listed in Table 2 .

A study from the Heymans Older Adults Center using a small sample evaluated the fecal microbial composition of older adults with frailty and found a significant reduction in the abundance of Bacteroides/Prevotella and F. prausnitzii. While the numbers of Enterobacteriaceae were higher (van Tongeren et al., 2005). Prevotella is a common constituent of the human intestinal microbiota, especially in the non-Westernized population. The succinate producer Prevotella copri improves glucose and insulin tolerance in people with fiber-rich diets, suggesting that the beneficial effects of Prevotella may be diet-dependent (Tett et al., 2019). F. prausnitzii is an important butyrate-producing bacteria with anti-inflammatory properties (Ferreira-Halder et al., 2017). In contrast, some forms of Enterobacteriaceae are opportunistic pathogens that can cause intestinal and extraintestinal infections (Sassone-Corsi et al., 2016).

The loss of community-associated microbiota is associated with increased frailty. Decreases in the numbers of taxa such as Ruminococcus and Prevotella, along with increases in the numbers of Alistipes and Oscillibacter, are correlated with several parameters of frailty (Claesson et al., 2012). These results suggest that the number of butyrate-producing genera is decreased, while the number of genera that can metabolize fermented products is increased. Butyrate helps suppress colonic inflammation and carcinogenesis (Fu et al., 2019), and it can directly acylate virulence factors to reduce the invasion and infection ability of pathogens such as Salmonella typhimurium (Michaudel and Sokol, 2020). In contrast, Alistipes is pathogenic in colorectal cancer and is related to mood disorders (Parker et al., 2020).

Jackson et al. reported a negative relationship between frailty and the alpha diversity of gut microbiota. In pre-frail individuals, Eubacterium dolichum and Eggerthella lenta are more abundant, while $F$. prausnitzii is less so (Jackson et al., 2016). E. lenta, which belongs to the Actinobacteria phylum, is associated with inflammation (Forbes et al., 2018), and is increasingly found in patients with severe comorbidities (Woerther et al., 2017).

Frailty has been demonstrated to be superior to chronological age in assessing the risk of age-related adverse health outcomes. A frailty-associated co-abundance module composed of Eggerthella, Coprobacillus, and Ruminococcus was identified in community-dwelling adults (Maffei et al., 2017). A short-term prospective longitudinal cohort study observed that, with increasing frailty, residents had lower abundances of butyrateproducing bacterium, particularly Clostridium cluster XIVa and Lachnospiraceae (Haran et al., 2018). Gut microbiota diversity and composition were also altered in late elderly hospitalized patients (Zhang et al., 2020).

In a recent study, Lim et al. analyzed the relationship between gut microbiota and frailty in 176 Korean older adults and found that in older adults with frailty, the abundance of $P$. copri and Coprococcus eutactus were decreased, while that of the opportunistic pathogens Bacteroides fragilis and Clostridium hathewayi were increased (Lim et al., 2021). Notably, the relative abundance of the butyrate-producing Coprococcus is negatively associated with atopic disease, depression and irritable bowel syndrome (Lim et al., 2021), while B. fragilis toxin triggers a pro-carcinogenic, multistep inflammatory cascade in colonic epithelial cells (Chung et al., 2018). In addition, in a recent study of older patients with chronic kidney disease, the alpha diversity of the gut microbiota community was found to be similar between the control and frail groups, except that Mogibacteriaceae, Coriobacteriaceae, and Eggerthella spp were more abundant in the frail subjects (Margiotta et al., 2020). Some of these bacteria, which include Coriobacteriaceae and Eggerthell, are correlated with the occurrence of neurological and psychiatric disorders, such as multiple sclerosis and major depressive disorder (Fung et al., 2017). 
TABLE 2 | Studies investigating the association between fecal microbiota composition and frailty in older adults.

\begin{tabular}{|c|c|c|c|c|c|c|c|c|}
\hline $\begin{array}{l}\text { Study } \\
\text { (year) }\end{array}$ & Country & Setting & $\begin{array}{l}\text { Group being } \\
\text { compared }\end{array}$ & $\begin{array}{l}\text { Number of } \\
\text { participants } \\
\text { T(F/C) }\end{array}$ & $\begin{array}{l}\text { Mean } \\
\text { age } \\
\text { (F/C) }\end{array}$ & $\begin{array}{l}\text { Method } \\
\text { of frailty }\end{array}$ & Mean finding in frailty group & $\begin{array}{c}\text { Microbiota } \\
\text { profiling }\end{array}$ \\
\hline $\begin{array}{l}\text { van } \\
\text { Tongeren } \\
\text { et al. } \\
\text { (2005) }\end{array}$ & Netherlands & Elderly Center & $\begin{array}{l}\text { Elderly with a } \\
\text { low frailty score } \\
\text { VS Elderly with a } \\
\text { high frailty score }\end{array}$ & $23(13 / 10)$ & $\begin{array}{l}\text { NAV } \\
\text { NA }\end{array}$ & GFI & $\begin{array}{l}\uparrow \text { Enterobacteriaceae } \\
\downarrow \text { Bacteroides/Prevotella Faecalibacterium } \\
\text { prausnitzii }\end{array}$ & $\begin{array}{l}\text { Fluorescent } \\
\text { in situ } \\
\text { hybridization }\end{array}$ \\
\hline $\begin{array}{l}\text { Claesson } \\
\text { et al. } \\
(2012)\end{array}$ & Irish & $\begin{array}{l}\text { Community, Out- } \\
\text { patient day hospital, } \\
\text { Shortterm rehabilitation } \\
\text { hospital, long-term } \\
\text { residential care }\end{array}$ & $\begin{array}{l}\text { Healthy } \\
\text { community } \\
\text { dwelling } \\
\text { subjects VS frail } \\
\text { long-term care } \\
\text { residents }\end{array}$ & 178 (NA/NA) & 78 & $\begin{array}{l}\text { Weight, } \\
\text { CC }\end{array}$ & $\begin{array}{l}\uparrow \text { Alistipes, Oscillibacter } \\
\downarrow \text { Ruminococcus, Prevotella }\end{array}$ & $\begin{array}{l}\text { 16S rRNA } \\
\text { sequencing }\end{array}$ \\
\hline $\begin{array}{l}\text { Jackson } \\
\text { et al. } \\
(2016)\end{array}$ & UK & Community & $\begin{array}{l}\text { Pre-frail VS Non- } \\
\text { frail }\end{array}$ & $\begin{array}{c}728(103 / \\
625)\end{array}$ & 63 & $\mathrm{FI}$ & $\begin{array}{l}\text { Frailty is negatively associated with alpha } \\
\text { diversity of the gut microbiota } \\
\uparrow \text { Eubacterium dolichum, Eggerthella lenta } \\
\downarrow \text { Faecalibacterium prausnitzii }\end{array}$ & $\begin{array}{l}16 \mathrm{~S} \text { rRNA } \\
\text { sequencing }\end{array}$ \\
\hline $\begin{array}{l}\text { Haran } \\
\text { et al. } \\
(2018)\end{array}$ & USA & Nursing home & $\begin{array}{l}\text { A prospective } \\
\text { longitudinal } \\
\text { cohort study }\end{array}$ & 23 & 82.7 & $\begin{array}{l}\text { CSHA- } \\
\text { CFS }\end{array}$ & $\downarrow$ Butyrate-producing organisms & $\begin{array}{l}16 \mathrm{~S} \text { rRNA } \\
\text { sequencing }\end{array}$ \\
\hline $\begin{array}{l}\text { Zhang } \\
\text { et al. } \\
\text { (2020) }\end{array}$ & China & Hospital & $\begin{array}{l}\text { Frailty group VS } \\
\text { Control group }\end{array}$ & $27(15 / 12)$ & $\begin{array}{l}82.0 / \\
81.2\end{array}$ & $\mathrm{FI}$ & $\begin{array}{l}\text { No differences in alpha diversity } \\
\uparrow \text { Acetanaerobacterium, Catenibacterium, } \\
\text { [Ruminococcus]_torques_group, DQ801572_g, } \\
\text { Ruminococcaceae_UCG_011, Prevotella_9, } \\
\text { Olsenella, EF434341_g, KF843164_g, } \\
\text { Pseudoxanthomonas } \\
\downarrow \text { Gemella, Lachnoanaerobaculum, } \\
\text { Eubacterium[U1]_ruminantium_group, } \\
\text { Azospira, Tyzzerella, Cloacibacterium, } \\
\text { EU455341_g genera }\end{array}$ & $\begin{array}{l}\text { 16S rRNA } \\
\text { sequencing }\end{array}$ \\
\hline $\begin{array}{l}\text { Picca } \\
\text { et al., } \\
(2019)\end{array}$ & Italy & Community & $\begin{array}{l}\text { PF\&S VS } \\
\text { NonPF\&S }\end{array}$ & $35(18 / 17)$ & $\begin{array}{l}75.7 / \\
73.9\end{array}$ & SPPB & $\begin{array}{l}\text { No differences in alpha diversity } \\
\uparrow \text { Oscillospira, Ruminococcus } \\
\downarrow \text { Barnesiellaceae, Christensenellaceae }\end{array}$ & $\begin{array}{l}16 \mathrm{~S} \text { rRNA } \\
\text { sequencing }\end{array}$ \\
\hline $\begin{array}{l}\text { Margiotta } \\
\text { et al. } \\
(2020)\end{array}$ & Italy & Hospital & $\begin{array}{l}\text { F-CKD VS NF- } \\
\text { CKD }\end{array}$ & $64(38 / 26)$ & $\begin{array}{l}81.8 / \\
79.0\end{array}$ & FFP & $\begin{array}{l}\text { No differences in alpha diversity } \\
\uparrow \text { Mogibacteriacee, Coriobacteriacee } \\
\text { Eggerthella }\end{array}$ & $\begin{array}{l}\text { 16S rRNA } \\
\text { sequencing }\end{array}$ \\
\hline $\begin{array}{l}\text { Lim et al. } \\
\text { (2021) }\end{array}$ & Korea & Community & $\begin{array}{l}\text { Frail VS Pre-frail } \\
\text { VS Robust }\end{array}$ & $\begin{array}{c}176(8 / 26 / \\
142)\end{array}$ & 74.7 & $\mathrm{FI}$ & $\begin{array}{l}\text { Fl scores were negatively associated with } \\
\text { microbial diversity } \\
\uparrow \text { Bacteroides fragilis Clostridium hathewayi } \\
\downarrow \text { Prevotella copri, Coprococcus eutactus }\end{array}$ & $\begin{array}{l}16 S \text { rRNA } \\
\text { sequencing }\end{array}$ \\
\hline
\end{tabular}

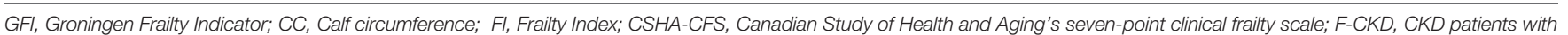

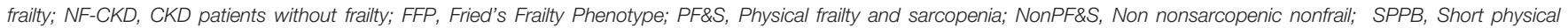
performance battery.

Sarcopenia is considered a premonitory state for frailty. Picca et al. found that microbial alpha diversity did not significantly differ between physical frailty and sarcopenia (PF\&S) and nonPF\&S groups. However, their microbial composition was significantly different (Picca et al., 2019). In the PF\&S group, Oscillospira and Ruminococcus were more abundant, whereas Barnesiellaceae and Christensenellaceae were less. Ruminococcus has been reported to accelerate the disease progression of amyotrophic lateral sclerosis in susceptible mice (Blacher et al., 2019). Ruminococcus and Oscillospira, which both belong to the order Clostridiales, are enriched in HIV-infected women (Wang et al., 2020). Christensenellaceae, which belongs to the bacterial phylum Firmicutes, is closely related to host health (Waters and Ley, 2019). The relative abundance of Christensenellaceae in the human gut is related to health status in multiple disease contexts, including metabolic disease and inflammatory bowel disease.

\section{CHRONIC LOW-GRADE INFLAMMATION: A DRIVER OF FRAILTY?}

Chronic low-grade inflammation is a low-grade, systemic, unresolved smoldering chronic inflammatory state first proposed by Krabbe et al. in 2004 (Krabbe et al., 2004). It is part of a spectrum of immunosenescence characteristics (Franceschi et al., 2000), of which the chronic activation of the innate immune system is a prominent feature (Franceschi et al., 2018). Chronic inflammation is a crucial driver of metabolic disorders and the age-related decline of physical functions. It may also be a risk factor for some age-related diseases, such as cancer, depression, sarcopenia, and disability (Cesari et al., 2004; Grivennikov et al., 2010; Kohler et al., 2016). These age-related diseases have similar mechanisms as those underlying the development of frailty. 
Sarcopenia is an age-related generalized skeletal muscle disorder characterized by decreased muscle mass and function. It is associated with a risk of adverse outcomes such as physical disability, low quality of life, and death, and it has strong links with physical frailty. Higher plasma concentrations of inflammatory biomarkers are associated with a decline in muscle mass and strength (Cesari et al., 2004). In contrast, long-term nonsteroidal anti-inflammatory drug (NSAID) use is linked to a decreased risk of muscle mass and loss of function (Landi et al., 2013).

More studies investigating the relationship between chronic low-grade inflammation and frailty may be helpful in developing scientific interventions. The mechanism may involve musculoskeletal metabolism and the endocrine and central nervous systems. Sarcopenia is considered the biological substrate for physical frailty and levels of the plasma inflammatory marker CRP are higher in patients with sarcopenia than in controls (Bano et al., 2017). Reduced muscle protein synthesis and increased muscle degradation are observed in pathological inflammation (Constantin et al., 2013; Wilson et al., 2017).

Chronic inflammation may also have adverse effects on the regenerative function of skeletal muscle satellite cells and can induce mitochondrial-mediated or death domain receptormediated apoptosis pathways in skeletal muscle cells (Jo et al., 2012; Walston, 2015). Insulin-like growth factor-1 (IGF-1) is related to many skeletal muscle anabolic pathways and can be used to delay the progression of muscle weakness. Under inflammatory conditions, it is maintained at relatively low levels. However, local expression of the IGF-1ea and IGF-1eb transgenes in aged transgenic mice can alleviate age-related losses of muscle mass and strength loss (Ascenzi et al., 2019). During senescence, lower levels of sex steroids, growth hormones, and vitamin D are associated with increased baseline levels of inflammatory proteins (Hunt et al., 2010). In addition, chronic low-grade inflammation can further promote anorexia of aging and is associated with reduced mobility and impaired cognitive function, which contribute to the development of physical and cognitive frailty (Greco et al., 2019).

\section{HOW DO GUT MICROBIOTA CAUSE FRAILTY?}

\section{The Gut Microbiota, Inflammation, and Intestinal Permeability; the Gut-Muscle Axis; and the Gut-Brain Axis}

The human gut microbiota is a complex and delicate commensal ecosystem affected by diet, metabolism, and immune function (Franceschi et al., 2018). The relationship between the host and healthy gut microbiota is mutually beneficial. The adaptability and plasticity of the gut microbiota allow them to affect the health and disease state of the host by adjusting immune and metabolic pathways. The aging-related remodeling of gut microbiota can facilitate the release of inflammatory products, programs diurnal rhythms in host metabolism (Kuang et al.,
2019), and interact with other organs and tissues. We hypothesize that changes in the gut microbiome may play a role in the pathogenesis of physical frailty by regulating gutderived chronic inflammation. We summarize the possible mechanisms in Figure 1.

\section{Increased Gut Permeability}

Zonulin and fatty acid-binding protein-2, as paracellular integrity molecules of the intestinal epithelium, are biomarkers of gut permeability and pathophysiological epithelium integrity. Dysbacteriosis can upregulate these molecules (Stevens et al., 2018). Serum concentrations of zonulin and high mobility group protein B1 increase with age and are negatively correlated with critical indices of age-related frailty, such as skeletal muscle strength and habitual physical activity (Qi et al., 2017).

Aged gut microbiota display a reduced capacity to counteract adverse microbes or remove their metabolites, which contributes to the activation of inflammatory reactions and the induction of immune disorders (Zhao, 2010). Aging-associated microbiota can promote intestinal permeability and inflammation and eventually increase the levels of frailty-related proinflammatory cytokines such as IL- 6 and TNF- $\alpha$ (Thevaranjan et al., 2017; Ticinesi et al., 2019). Fransen et al. transplanted gut microbiota from old conventional mice into young germ-free (GF) mice. They found that certain microbiota changes (i.e., lower levels of Akkermansia and higher levels of TM7 bacteria and Proteobacteria) can contribute to inflammation in the small intestine and promote the leakage of inflammatory bacterial components into the circulation (Fransen et al., 2017). Studies in fruit flies have indicated that changes in microbiota precede and can predict aged-related intestinal barrier dysfunction and rapid health decline (Clark et al., 2015). Alterations in the microbiota that occur prior to intestinal barrier dysfunction are conductive to intestinal immune activation and modulate excretory function. In contrast, microbiota composition changes that occur after intestinal barrier dysfunction result in systemic immune activation and organismal death.

At the onset of solid food ingestion, the metabolites produced by the microbiota, such as butyrate, contribute to intestinal barrier maturation at the suckling-to-weaning transition. Gutmicrobiota-derived metabolites have been suggested as a reasonable approach to maintain intestinal homeostasis (Beaumont et al., 2020). The most important gut microbial metabolites include short-chain fatty acids (SCFAs), amino acids, polyamines, bile acids, and lipids. Between these, SCFAs have been extensively studied and lower levels of SCFA are associated with age-related frailty (Nagpal et al., 2018). For example, the proportion of SCFAs-generating bacteria are decreased in nursing home residents with frailty (Haran et al., 2018). SCFAs can enhance intestinal barrier function by regulating tight junction proteins, including claudin-1, occludin, and zonula occludens-1. Additionally, it may induce hypoxia-inducible factor in intestinal epithelial cells and stimulate mucin secretion (Feng et al., 2018).

Intestinal dysbacteriosis contributes to increased lipopolysaccharide (LPS) expression, activation of the Tolllike receptor and degradation of the mucus layer, which lead to 


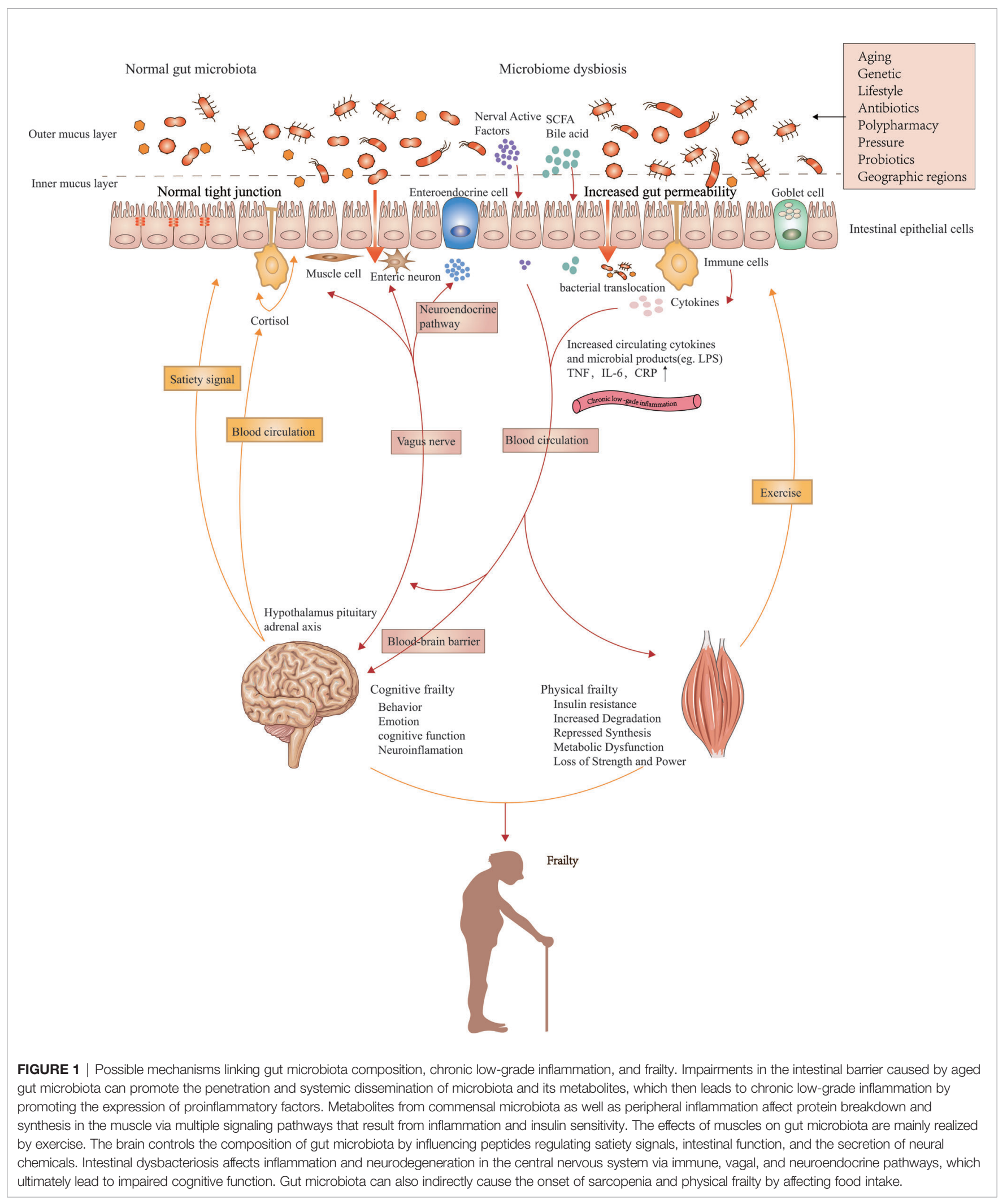

metabolic derangements. This process includes proinflammatory changes associated with intestinal barrier disruption such as alterations in the population of intestinal lamina propria cells and in the cytokine landscape. Bacteria or their products can enter the circulation through a damaged gut barrier. Some bacterial metabolites, such as phenylacetic acid, trimethylamine, 
or pathogen-associated-molecular-patterns, can promote chronic low-grade inflammation by inducing proinflammatory cytokines (Tilg et al., 2020).

\section{Changes in the Gut-Muscle Axis}

Sarcopenia is an age-related generalized skeletal muscle disorder characterized by decreased muscle mass and function. It is associated with a risk of adverse outcomes such as physical disability, poor quality of life, or death, and it is strongly linked with physical frailty (Mijnarends et al., 2015; Picca et al., 2019). Sarcopenia and physical frailty have partially overlapping diagnostic criteria, such as loss of strength and decreased physical activity. Muscle mass depletion and the reduction of muscle function are the main indicators of physical frailty and sarcopenia. According to Mijnarends et al., sarcopenia is a central manifestation and a key component of frailty. Frail elderly have a $60 \%$ risk of suffering from sarcopenia (Mijnarends et al., 2015). Sarcopenia is considered the biological basis of physical frailty and is related to the physiopathologic pathways underlying the negative healthrelated outcomes of frailty (Landi et al., 2015).

Numerous experiments in animals indicate possible links between intestinal dysbacteriosis and muscle mass, muscle function, and physical performance. Lahiri et al. compared the skeletal muscles of GF mice with those of specific-pathogenfree (SPF) mice with a gut microbiota. GF mice displayed reduced muscle mass and strength, decreased IGF-1 expression, and reduced transcription of genes related to skeletal muscle growth and mitochondrial function. The transplantation of gut microbiota from SPF mice into GF mice improved skeletal muscle mass and the oxidative metabolic capacity of muscles (Lahiri et al., 2019), and SCFA supplementation reduced the muscle damage in GF mice. Clinically, few related studies are available, and those that do exist mainly use probiotic interventions. For example, Buigues et al. founded that compared with placebo, prebiotic administration greatly improved exhaustion and handgrip strength, which are two criteria for frailty (Buigues et al., 2016). Moreover, short-term synbiotic use can alter the gut microbiota composition and reduce pro-inflammatory cytokine TNF- $\alpha$ levels in older adults (Macfarlane et al., 2013).

The effects of muscles on the gut microbiota are mainly realized by exercise. Professional athletes have a higher diversity of gut microbiota (Clarke et al., 2014). Petersen et al. analyzed the gut microbiomes in competitive cyclists. They found that the time spent exercising per week was related to high abundances of Prevotella, which was correlated with a number of amino acid and carbohydrate metabolism pathways (Petersen et al., 2017). Exercise induces changes in gut microbiota composition and metabolic capacity, and these changes are contingent on obesity status. However, excessive training may contribute to dysfunction of the intestinal mucosa, which increases and decreases, respectively, the tendencies for opportunistic pathogens and antiinflammatory bacteria (Karl et al., 2017). The effects of exercise on gut microbiota have been corroborated by animal experiments. The changes in the gut microbiota following exercise is conducive to the suppression of gut inflammation and an increase in energy harvest (Lamoureux et al., 2017; Allen et al., 2018).

The effects of an altered gut microbiota on muscle mass and function may be mediated by potential mechanisms involving metabolites or the endocrine or immune systems. The exposure of GF mice to microbiota can increase both bone formation and resorption (Yan et al., 2016). This process is accompanied by increases in IGF-1, a survival factor that is known to affect the growth and regeneration of skeletal muscle (Yan et al., 2016). One strain of Escherichia coli has been observed to prevent muscle wasting in mice with infections or physical damage to the intestine by acting on IGF-1 signaling in skeletal muscle; this effect depends on the NLRC4 inflammasome (Palaferri Schieber et al., 2015). Ghrelin is essential for the maintenance of aging muscles. In old ghrelin-deficient mice, fasting-induced muscle loss is exacerbated. The absence of ghrelin is associated with a proinflammatory microbiome profile, which is manifested in reduced levels of the butyrate-producing bacteria Roseburia and Clostridium cluster XIVb (Wu et al., 2020). Under conditions of adaptive immune deficiency, gut microbiota can promote a change from a pro-metabolic to a proimmune phenotype by increasing interferon-related genes and suppressing metabolic genes related to lipid absorption. These changes ultimately lead to muscle wastage and weight loss (Chassaing et al., 2012).

Changes in gut microbiota can influence the inflammatory state of the body. More specifically, chronic low-grade inflammation can affect protein breakdown and synthesis in muscle via various signaling pathways (e.g., the ubiquitinproteasome pathway, calpains, autophagy pathway, and apoptosis), which then lead to losses in muscle quality, strength, and function (Dalle et al., 2017). Increases in TNF- $\alpha$, IL-6, and fatty free acids seem to contribute to skeletal muscle proteolysis and insulin resistance, two main factors in several forms of muscle atrophy (Xia et al., 2017). In old rats, the use of NSAIDs increases muscle protein synthesis and decreases proteolysis (Rieu et al., 2009). Therefore, the control of intestinal-originating chronic low-grade inflammation may be therapeutic in preventing sarcopenia and limiting muscle strength loss (Przewlocka et al., 2020).

Obesity status, exercise modality, and exercise intensity may mediate the gut microbiota changes that are induced by exercise, which are largely unrelated to diet. Mailing et al. summarized the potential mechanisms underlying the effect of exercise on gut microbiota, which mainly involve ischemia, heat stress, metabolic flux, gut barrier, mucus layer, gut motility, mechanical forces, the vagus nerve/enteric nervous system, hormones/myokines, and bile acids. Some believe that intestinal immunity plays an important role in this process (Mailing LJ et al., 2019). Moderate-intensity exercise may improve intestinal immunity by increasing lymphocyte proliferation (Valdes-Ramos et al., 2010). Further, $\gamma \delta$ 
intraepithelial lymphocytes of the small intestine are critical mediators in the homeostasis between host and gut microbiota at the intestinal mucosal surface (Ismail et al., 2011). Highintensity exercise can result in brief intestinal permeability and increase the contact between gut microbiota and the immune system, which can then impact gut microbial communities.

\section{Changes in the Gut-Brain Axis}

The gut-brain axis is a duplex information system linking the intestine with the central nervous system (CNS). Stress signals from the brain can impact gastrointestinal function and gut microbiota composition via the efferent nerves and the hypothalamic-pituitary-adrenal (HPA) axis (Cox and Weiner, 2018). The continuous activation of the HPA axis increases the secretion of cortisol, which can then regulate the neuro immune signal response and affect the integrity of the intestinal barrier (Morais et al., 2021). Conversely, the effect of the gut microbiota on the brain mainly involves neural, endocrine, and immune pathways. Gut microbiota can directly or indirectly affect the nervous system by producing metabolites, acting on the neuroendocrine system, and regulating neurotransmitter concentrations. Gut microbiota and its metabolites can also affect the brain and thereby behavior by acting on the vagus nerve and enteric nervous system (Morais et al., 2021).

Dysregulation of the microbiota-gut-brain axis is involved in the pathophysiology of several neurological disorders, such as Alzheimer's disease (AD), autism spectrum disorder, brain injury, multiple sclerosis, and stroke (Cryan et al., 2020). Many clinical and animal studies confirm the link between the two-way communication between the gut microbiota and the brain with cognitive impairment. In human studies, the changes in the gut microbiota in patients with mild cognitive impairment are similar to those of $\mathrm{AD}$, suggesting that the gut microbiota are involved in the early pathogenesis of AD (Li et al., 2019). A model based on specific bacteria and SCFAs can accurately predict post-stroke cognitive impairments after stroke onset (Liu et al., 2020). Therapeutic strategies of gut microbiota regulation such as probiotics or fecal microbiota transplantation can be an effective way to prevent or treat cognitive impairment (Sun et al., 2020).

In animal studies, traumatic brain injury in mice changes the gastrointestinal tract as indicated by increased intestinal permeability and bacterial translocation (Ma et al., 2017). Older mice exhibit spatial memory deficits and increased anxiety-like behaviors relative to younger mice, and they also have increased gut permeability and levels of peripheral pro-inflammatory cytokines. Age-related alterations in the microbiota (e.g., the phylum TM7, the family Porphyromonadaceae, and the genus Odoribacter) are similar to those in many inflammatory diseases. From these, Porphyromonadaceae is relevant to cognitive impairment and affective disorders. Scott et al. proposed that changes in gut microbiota that may be involved in behavior impairment and affective and cognitive functions are also involved in gut permeability and peripheral inflammation (Scott et al., 2017). Moreover, probiotics supplementation may delay the onset of aging-related cognitive deficits (Yang et al., 2020).
Changes in gut barrier permeability and the blood-brain barrier affect the gut-brain axis (Osadchiy et al., 2019). In the drosophila dementia model, intestinal microflora dysbiosis is correlated to tumor necrosis factor- and c-Jun N-terminal kinase (JNK)-mediated inflammatory deterioration as well as to neurodegenerative brain pathways (Wu et al., 2017). Increased JNK activity can cause intestinal barrier dysfunction and microbial dysbiosis in the drosophila intestinal tumor model and mediate inflammatory deterioration via dysplasia of the drosophila midgut (Zhou and Boutros, 2020; Tamamouna et al., 2020). Peripheral inflammation can also lead to impaired cognitive function by directly affecting neuroimmune processes in the CNS. In an aging $\mathrm{AD}$ mouse model, changes in gut microbiota composition stimulate neuroinflammation by promoting the accumulation of phenylalanine and isoleucine (Wang et al., 2019). The metabolites of dietary tryptophan, which are controlled by commensal microbiota, can directly act on microglia and astrocytes in the CNS via the aryl hydrocarbon receptor to control inflammation and neurodegeneration (Rothhammer et al., 2018). The decreases in SCFAs produced by gut microbiota can potentially reduce amyloid deposition in both the brain and the gut (Zhang et al., 2017).

Certain bacterial components and metabolites that depend on bacterial growth cycles can stimulate intestinal satiety pathways (Fetissov, 2017). A review by Fetissov et al. proposed an integrative model of appetite control. According to this model, the short- and long-term regulation of appetite may involve the integration of signals from both the host and the bacteria. In animals, high doses of LPS reduce food intake. LPS can activate intracellular signaling pathways, increase levels of the proinflammatory mediator IL-1 $\beta$, and further induce a chronic inflammatory state that includes hypothalamic inflammation. This process is similar to the expression pattern of neuropeptides in obesity, anorexia nervosa, and cachexia. Altogether, these findings suggest that gut microbiota can indirectly induce sarcopenia and physical frailty in older patients by promoting malnutrition (Ticinesi et al., 2019).

\section{CONCLUSIONS AND FUTURE PERSPECTIVES}

Studies have established that inflammation, characterized by elevated levels of blood inflammatory markers, contributes to the development of frailty in older adults. Alterations in gut microbiota composition and its metabolites may be key regulators in mediating chronic inflammation in frailty. However, animal models of frailty are in its early phases, and the empirical data is lacking. The present studies on gut microbiota and frailty are mainly clinical crosssectional studies. Genetics, age, gender, nutrition intake, lifestyle, polypharmacy, social vulnerability, and geographic regions may all influence gut microbiota composition and function. Consequently, personalized regulation based on gut microbiota is necessary. 
Developing a verifiable predictive model for gut microbiota and frailty in older adults via large scale longitudinal research may help in determining the causal relationship between microbiota and disease, as well as in its early diagnosis and intervention.

\section{AUTHOR CONTRIBUTIONS}

Data analyses and wrote the manuscript: YX, DC, MW, and XJ. Manuscript preparation: XJL and XXL. Study design, project

\section{REFERENCES}

Adriansjach, J., Baum, S. T., Lefkowitz, E. J., Van Der Pol, W. J., Buford, T. W., and Colman, R. J. (2020). Age-Related Differences in the Gut Microbiome of Rhesus Macaques. J. Gerontol. A. Biol. Sci. Med. Sci. 75 (7), 1293-1298. doi: 10.1093/gerona/glaa048

Allen, J. M., Mailing, L. J., Cohrs, J., Salmonson, C., Fryer, J. D., Nehra, V., et al. (2018). Exercise Training-Induced Modification of the Gut Microbiota Persists After Microbiota Colonization and Attenuates the Response to ChemicallyInduced Colitis in Gnotobiotic Mice. Gut Microbes 9 (2), 115-130. doi: 10.1080/19490976.2017.1372077

Ascenzi, F., Barberi, L., Dobrowolny, G., Villa Nova Bacurau, A., Nicoletti, C., Rizzuto, E., et al. (2019). Effects of IGF-1 Isoforms on Muscle Growth and Sarcopenia. Aging Cell 18 (3), e12954. doi: 10.1111/acel.12954

Bana, B., and Cabreiro, F. (2019). The Microbiome and Aging. Annu. Rev. Genet. 53, 239-261. doi: 10.1146/annurev-genet-112618-043650

Bano, G., Trevisan, C., Carraro, S., Solmi, M., Luchini, C., Stubbs, B., et al. (2017). Inflammation and Sarcopenia: A Systematic Review and Meta-Analysis. Maturitas 96, 10-15. doi: 10.1016/j.maturitas.2016.11.006

Beaumont, M., Paës, C., Mussard, E., Knudsen, C., Cauquil, L., Aymard, P., et al. (2020). Gut Microbiota Derived Metabolites Contribute to Intestinal Barrier Maturation at the Suckling-to-Weaning Transition. Gut Microbes 11 (5), 12681286. doi: 10.1080/19490976.2020.1747335

Biagi, E., Nylund, L., Candela, M., Ostan, R., Bucci, L., Pini, E., et al. (2010). Through Ageing, and Beyond: Gut Microbiota and Inflammatory Status in Seniors and Centenarians. PloS One 5 (5), e10667. doi: 10.1371/annotation/ df45912f-d15c-44ab-8312-e7ec0607604d

Biagi, E., Franceschi, C., Rampelli, S., Severgnini, M., Ostan, R., Turroni, S., et al. (2016). Gut Microbiota and Extreme Longevity. Curr. Biol. 26 (11), 1480-1485. doi: 10.1016/j.cub.2016.04.016

Bian, G., Gloor, G. B., Gong, A., Jia, C., Zhang, W., Hu, J., et al. (2017). The Gut Microbiota of Healthy Aged Chinese is Similar to That of the Healthy Young. mSphere 2 (5). doi: 10.1128/mSphere.00327-17

Bischoff, S. C. (2016). Microbiota and Aging. Curr. Opin. Clin. Nutr. Metab. Care 19 (1), 26-30. doi: 10.1097/MCO.0000000000000242

Blacher, E., Bashiardes, S., Shapiro, H., Rothschild, D., Mor, U., Dori-Bachash, M., et al. (2019). Potential Roles of Gut Microbiome and Metabolites in Modulating ALS in Mice. Nature 572 (7770), 474-480. doi: 10.1038/s41586019-1443-5

Buigues, C., Fernandez-Garrido, J., Pruimboom, L., Hoogland, A. J., NavarroMartinez, R., Martinez-Martinez, M., et al. (2016). Effect of a Prebiotic Formulation on Frailty Syndrome: A Randomized, Double-Blind Clinical Trial. Int. J. Mol. Sci. 17 (6), 932. doi: 10.3390/ijms17060932

Butcher, L., Carnicero, J. A., Gomez Cabrero, D., Dartigues, J. F., Peres, K., GarciaGarcia, F. J., et al. (2019). Increased Levels of Soluble Receptor for Advanced Glycation End-Products (RAGE) Are Associated With a Higher Risk of Mortality in Frail Older Adults. Age Ageing 48 (5), 696-702. doi: 10.1093/ ageing/afz073

Castellana, F., Lampignano, L., Bortone, I., Zupo, R., Lozupone, M., Griseta, C., et al. (2021). Physical Frailty, Multimorbidity, and All-Cause Mortality in an Older Population From Southern Italy: Results From the Salus in Apulia Study. J. Am. Med. Dir Assoc. 22 (3), 598-605. doi: 10.1016/j.jamda.2020.12.026 management, financial support, and manuscript revision: ZX. All authors contributed to the article and approved the submitted version.

\section{FUNDING}

This study was supported by the National Key Research and Development Program of China (2018YFC2002000).

Cesari, M., Penninx, B. W., Pahor, M., Lauretani, F., Corsi, A. M., Rhys Williams, G., et al. (2004). Inflammatory Markers and Physical Performance in Older Persons: The InCHIANTI Study. J. Gerontol. A. Biol. Sci. Med. Sci. 59 (3), 242 248. doi: 10.1093/gerona/59.3.M242

Cesari, M., Gambassi, G., van Kan, G. A., and Vellas, B. (2014). The Frailty Phenotype and the Frailty Index: Different Instruments for Different Purposes. Age Ageing 43 (1), 10-12. doi: 10.1093/ageing/aft160

Chassaing, B., Aitken, J. D., Gewirtz, A. T., and Vijay-Kumar, M. (2012). Gut Microbiota Drives Metabolic Disease in Immunologically Altered Mice. Adv. Immunol. 116, 93-112. doi: 10.1016/B978-0-12-394300-2.00003-X

Chung, L., Thiele Orberg, E., Geis, A. L., Chan, J. L., Fu, K., and DeStefano Shields, C. E. (2018). Bacteroides Fragilis Toxin Coordinates a Pro-carcinogenic Inflammatory Cascade Via Targeting of Colonic Epithelial Cells. Cell Host Microbe 23 (2), 203-214 e5. doi: 10.1016/j.chom.2018.02.004

Claesson, M. J., Cusack, S., O'Sullivan, O., Greene-Diniz, R., de Weerd, H., Flannery, E., et al. (20111). Composition, Variability, and Temporal Stability of the Intestinal Microbiota of the Elderly. Proc. Natl. Acad. Sci. U. S. A. 108 (Suppl 1), 4586-4591. doi: 10.1073/pnas.1000097107

Claesson, M. J., Jeffery, I. B., Conde, S., Power, S. E., O'Connor, E. M., Cusack, S., et al. (2012). Gut Microbiota Composition Correlates With Diet and Health in the Elderly. Nature 488 (7410), 178-184. doi: 10.1038/nature11319

Clarke, S. F., Murphy, E. F., O'Sullivan, O., Lucey, A. J., Humphreys, M., Hogan, A., et al. (2014). Exercise and Associated Dietary Extremes Impact on Gut Microbial Diversity. Gut 63 (12), 1913-1920. doi: 10.1136/gutjnl-2013-306541

Clark, R. I., Salazar, A., Yamada, R., Fitz-Gibbon, S., Morselli, M., Alcaraz, J., et al. (2015). Distinct Shifts in Microbiota Composition During Drosophila Aging Impair Intestinal Function and Drive Mortality. Cell Rep. 12 (10), 1656-1667. doi: 10.1016/j.celrep.2015.08.004

Collard, R. M., Boter, H., Schoevers, R. A., and Oude Voshaar, R. C. (2012). Prevalence of Frailty in Community-Dwelling Older Persons: A Systematic Review. J. Am. Geriatr. Soc. 60 (8), 1487-1492. doi: 10.1111/j.15325415.2012.04054.x

Constantin, D., Menon, M. K., Houchen-Wolloff, L., Morgan, M. D., Singh, S. J., Greenhaff, P., et al. (2013). Skeletal Muscle Molecular Responses to Resistance Training and Dietary Supplementation in COPD. Thorax 68 (7), 625-633. doi: 10.1136/thoraxjnl-2012-202764

Cox, L. M., and Weiner, H. L. (2018). Microbiota Signaling Pathways That Influence Neurologic Disease. Neurotherapeutics 15 (1), 135-145. doi: 10.1007/s13311-017-0598-8

Cryan, J. F., O'Riordan, K. J., Sandhu, K., Peterson, V., and Dinan, T. G. (2020). The Gut Microbiome in Neurological Disorders. Lancet Neurol. 19 (2), 179194. doi: 10.1016/S1474-4422(19)30356-4

Dalle, S., Rossmeislova, L., and Koppo, K. (2017). The Role of Inflammation in Age-Related Sarcopenia. Front. Physiol. 8, 1045. doi: 10.3389/fphys.2017.01045

Dao, M. C., Everard, A., Aron-Wisnewsky, J., Sokolovska, N., Prifti, E., Verger, E. O., et al. (2016). Akkermansia Muciniphila and Improved Metabolic Health During a Dietary Intervention in Obesity: Relationship With Gut Microbiome Richness and Ecology. Gut 65 (3), 426-436. doi: 10.1136/ gutjnl-2014-308778

DeJong, E. N., Surette, M. G., and Bowdish, D. M. E. (2020). The Gut Microbiota and Unhealthy Aging: Disentangling Cause From Consequence. Cell Host Microbe 28 (2), 180-189. doi: 10.1016/j.chom.2020.07.013 
Feng, W., Ao, H., and Peng, C. (2018). Gut Microbiota, Short-Chain Fatty Acids, and Herbal Medicines. Front. Pharmacol. 9, 1354. doi: 10.3389/ fphar.2018.01354

Fernández-Garrido, J., Navarro-Martínez, R., Buigues-González, C., MartínezMartínez, M., Ruiz-Ros, V., and Cauli, O. (2014). The Value of Neutrophil and Lymphocyte Count in Frail Older Women. Exp. Gerontol. 54, 35-41. doi: 10.1016/j.exger.2013.11.019

Ferreira-Halder, C. V., Faria, A. V. S., and Andrade, S. S. (2017). Action and Function of Faecalibacterium Prausnitzii in Health and Disease. Best Pract. Res. Clin. Gastroenterol. 31 (6), 643-648. doi: 10.1016/j.bpg.2017.09.011

Fetissov, S. O. (2017). Role of the Gut Microbiota in Host Appetite Control: Bacterial Growth to Animal Feeding Behaviour. Nat. Rev. Endocrinol. 13 (1), 11-25. doi: 10.1038/nrendo.2016.150

Finlay, B. B., Pettersson, S., Melby, M. K., and Bosch, T. C. G. (2019). The Microbiome Mediates Environmental Effects on Aging. Bioessays 41 (10), e1800257. doi: 10.1002/bies.201800257

Fontana, L., Addante, F., Copetti, M., Paroni, G., Fontana, A., Sancarlo, D., et al. (2013). Identification of a Metabolic Signature for Multidimensional Impairment and Mortality Risk in Hospitalized Older Patients. Aging Cell 12 (3), 459-466. doi: 10.1111/acel.12068

Forbes, J. D., Chen, C-y., Knox, N. C., Marrie, R. A., El-Gabalawy, H., de Kievit, T., et al. (2018). A Comparative Study of the Gut Microbiota in Immune-Mediated Inflammatory Diseases-Does a Common Dysbiosis Exist? Microbiome 6 (1), 221. doi: 10.1186/s40168-018-0603-4

Franceschi C, B. M., and Valensin, S. (2000). Inflamm-Aging. Evolutionary Perspective Immunosenescence Ann. New Y. Acad. Sci. 908, 244-254. doi: 10.1111/j.1749-6632.2000.tb06651.x

Franceschi, C., Bonafè, M., and Valensin, S. (2000). Inflamm-Aging. An Evolutionary Perspective on Immunosenescence. Ann. N. Y. Acad. Sci. 908, 244-254. doi: 10.1111/j.1749-6632.2000.tb06651.x

Franceschi, C., Garagnani, P., Parini, P., Giuliani, C., and Santoro, A. (2018). Inflammaging: A New Immune-Metabolic Viewpoint for Age-Related Diseases. Nat. Rev. Endocrinol. 14 (10), 576-590. doi: 10.1038/s41574-0180059-4

Fransen, F., van Beek, A. A., Borghuis, T., Aidy, S. E., Hugenholtz, F., and van der Gaast-de Jongh, C. (2017). Aged Gut Microbiota Contributes to Systemical Inflammaging After Transfer to Germ-Free Mice. Front. Immunol. 8, 1385. doi: 10.3389/fimmu.2017.01385

Fu, X., Liu, Z., Zhu, C., Mou, H., and Kong, Q. (2019). Nondigestible Carbohydrates, Butyrate, and Butyrate-Producing Bacteria. Crit. Rev. Food Sci. Nutr. 59 (sup1), S130-S152. doi: 10.1080/10408398.2018. 1542587

Fung, T. C., Olson, C. A., and Hsiao, E. Y. (2017). Interactions Between the Microbiota, Immune and Nervous Systems in Health and Disease. Nat. Neurosci. 20 (2), 145-155. doi: 10.1038/nn.4476

Furtado, G. E., Uba Chupel, M., Minuzzi, L., Patrício, M., Loureiro, M., Bandelow, S., et al. (2020). Exploring the Potential of Salivary and Blood Immune Biomarkers to Elucidate Physical Frailty in Institutionalized Older Women. Exp. Gerontol. 129, 110759. doi: 10.1016/j.exger.2019.110759

Greco, E. A., Pietschmann, P., and Migliaccio, S. (2019). Osteoporosis and Sarcopenia Increase Frailty Syndrome in the Elderly. Front. Endocrinol. (Lausanne) 10, 255. doi: 10.3389/fendo.2019.00255

Grivennikov, S. I., Greten, F. R., and Karin, M. (2010). Immunity, Inflammation, and Cancer. Cell 140 (6), 883-899. doi: 10.1016/j.cell.2010.01.025

Haran, J. P., Bucci, V., Dutta, P., Ward, D., and McCormick, B. (2018). The Nursing Home Elder Microbiome Stability and Associations With Age, Frailty, Nutrition and Physical Location. J. Med. Microbiol. 67 (1), 40-51. doi: 10.1099/ jmm. 0.000640

Hirani, V., Blyth, F., Naganathan, V., Le Couteur, D. G., Seibel, M. J., Waite, L. M., et al. (2015). Sarcopenia is Associated With Incident Disability, Institutionalization, and Mortality in Community-Dwelling Older Men: The Concord Health and Ageing in Men Project. J. Am. Med. Dir Assoc. 16 (7), 607-613. doi: 10.1016/j.jamda.2015.02.006

Hsu, B., Hirani, V., Cumming, R. G., Naganathan, V., Blyth, F. M., Wright, F. C., et al. (2019). Cross-Sectional and Longitudinal Relationships Between Inflammatory Biomarkers and Frailty in Community-dwelling Older Men: The Concord Health and Ageing in Men Project. J. Gerontol. A. Biol. Sci. Med. Sci. 74 (6), 835-841. doi: 10.1093/gerona/glx142
Hunt, K. J., Walsh, B. M., Voegeli, D., and Roberts, H. C. (2010). Inflammation in Aging Part 1: Physiology and Immunological Mechanisms. Biol. Res. Nurs. 11 (3), 245-252. doi: 10.1177/1099800409352237

Ismail, A. S., Severson, K. M., Vaishnava, S., Behrendt, C. L., Yu, X., Benjamin, J. L., et al. (2011). Gammadelta Intraepithelial Lymphocytes are Essential Mediators of Host-Microbial Homeostasis at the Intestinal Mucosal Surface. Proc. Natl. Acad. Sci. U. S. A. 108 (21), 8743-8748. doi: 10.1073/pnas.1019574108

Jackson, M. A., Jeffery, I. B., Beaumont, M., Bell, J. T., Clark, A. G., Ley, R. E., et al. (2016). Signatures of Early Frailty in the Gut Microbiota. Genome Med. 8 (1), 8. doi: 10.1186/s13073-016-0262-7

Jayanama, K., and Theou, O. (2019). Effects of Probiotics and Prebiotics on Frailty and Ageing: A Narrative Review. Curr. Clin. Pharmacol 15(3), 183-192. doi: 10.2174/1574884714666191120124548

Jo, E., Lee, S. R., Park, B. S., and Kim, J. S. (2012). Potential Mechanisms Underlying the Role of Chronic Inflammation in Age-Related Muscle Wasting. Aging Clin. Exp. Res. 24 (5), 412-422.

Karl, J. P., Margolis, L. M., Madslien, E. H., Murphy, N. E., Castellani, J. W., Gundersen, Y., et al. (2017). Changes in Intestinal Microbiota Composition and Metabolism Coincide With Increased Intestinal Permeability in Young Adults Under Prolonged Physiological Stress. Am. J. Physiol. Gastrointest Liver Physiol. 312 (6), G559-G571. doi: 10.1152/ajpgi.00066.2017

Kohler, O., Krogh, J., Mors, O., and Benros, M. E. (2016). Inflammation in Depression and the Potential for Anti-Inflammatory Treatment. Curr. Neuropharmacol. 14 (7), 732-742. doi: 10.2174/1570159X14666151208113700

Kong, F., Deng, F., Li, Y., and Zhao, J. (2019). Identification of Gut Microbiome Signatures Associated With Longevity Provides a Promising Modulation Target for Healthy Aging. Gut Microbes 10 (2), 210-215. doi: 10.1080/ 19490976.2018.1494102

Krabbe, K. S., Pedersen, M., and Bruunsgaard, H. (2004). Inflammatory Mediators in the Elderly. Exp. Gerontol. 39 (5), 687-699. doi: 10.1016/j.exger.2004.01.009

Kuang, Z., Wang, Y., Li, Y., Ye, C., Ruhn, K. A., Behrendt, C. L., et al. (2019). The Intestinal Microbiota Programs Diurnal Rhythms in Host Metabolism Through Histone Deacetylase 3. Science 365 (6460), 1428-1434. doi: 10.1126/science.aaw3134

Lahiri, S., Garcia-Perez, I., Reza, M. M., Martin, K. A., Kundu, P., et al. (2019). The Gut Microbiota Influences Skeletal Muscle Mass and Function in Mice. Sci. Transl. Med. 11 (502). doi: 10.1126/scitranslmed.aan5662

Lamoureux, E. V., Grandy, S. A., and Langille, M. G. I. (2017). Moderate Exercise has Limited But Distinguishable Effects on the Mouse Microbiome. mSystems 2 (4), e00006-17. doi: 10.1128/mSystems.00006-17

Landi, F., Marzetti, E., Liperoti, R., Pahor, M., Russo, A., Martone, A. M., et al. (2013). Nonsteroidal Anti-Inflammatory Drug (NSAID) Use and Sarcopenia in Older People: Results From the ilSIRENTE Study. J. Am. Med. Dir Assoc. 14 (8), 626.e9-626.13. doi: 10.1016/j.jamda.2013.04.012

Landi, F., Calvani, R., Cesari, M., Tosato, M., Martone, A. M., Bernabei, R., et al. (2015). Sarcopenia as the Biological Substrate of Physical Frailty. Clin. Geriatr. Med. 31 (3), 367-374. doi: 10.1016/j.cger.2015.04.005

Lee, W. J., Chen, L. K., Liang, C. K., Peng, L. N., Chiou, S. T., and Chou, P. (2016). Independent of IL-6, is Associated With Prevalent Frailty in CommunityDwelling Elderly Taiwanese People. PloS One 11 (6), e0157877. doi: 10.1371/ journal.pone. 0157877

Li, B., He, Y., Ma, J., Huang, P., Du, J., Cao, L., et al. (2019). Mild Cognitive Impairment has Similar Alterations as Alzheimer's Disease in Gut Microbiota. Alzheimers Dement 15 (10), 1357-1366. doi: 10.1016/j.jalz.2019.07.002

Lim, M. Y., Hong, S., Kim, J. H., and Nam, Y. D. (2021). Association Between Gut Microbiome and Frailty in the Older Adult Population in Korea. J. Gerontol. A. Biol. Sci. Med. Sci glaa319. doi: 10.1093/gerona/glaa319

Li, H., Qi, Y., and Jasper, H. (2016). Preventing Age-Related Decline of Gut Compartmentalization Limits Microbiota Dysbiosis and Extends Lifespan. Cell Host Microbe 19 (2), 240-253. doi: 10.1016/j.chom.2016.01.008

Liu, H., Wang, J., He, T., Becker, S., Zhang, G., Li, D., et al. (2018). Butyrate: A Double-Edged Sword for Health? Adv. Nutr. 9 (1), 21-29. doi: 10.1093/ advances/nmx009

Liu, Y., Kong, C., Gong, L., Zhang, X., Zhu, Y., Wang, H., et al. (2020). The Association of Post-Stroke Cognitive Impairment and Gut Microbiota and Its Corresponding Metabolites. J. Alzheimers Dis. 73 (4), 1455-1466. doi: 10.3233/ JAD-191066 
Lu, Y., Tan,C., Nyunt, M. S., Mok, E. W., Camous, X., Kared, H., et al. (2016). Inflammatory and Immune Markers Associated With Physical Frailty Syndrome: Findings From Singapore Longitudinal Aging Studies. Oncotarget 7 (20), 28783-28795. doi: 10.18632/oncotarget.8939

Macfarlane, S., Cleary, S., Bahrami, B., Reynolds, N., and Macfarlane, G. T. (2013). Synbiotic Consumption Changes the Metabolism and Composition of the Gut Microbiota in Older People and Modifies Inflammatory Processes: A Randomised, Double-Blind, Placebo-Controlled Crossover Study. Aliment Pharmacol. Ther. 38 (7), 804-816. doi: 10.1111/apt.12453

Ma, E. L., Smith, A. D., Desai, N., Cheung, L., Hanscom, M., Stoica, B. A., et al. (2017). Bidirectional Brain-Gut Interactions and Chronic Pathological Changes After Traumatic Brain Injury in Mice. Brain Behav. Immun. 66, 56-69. doi: 10.1016/j.bbi.2017.06.018

Maffei, V. J., Kim, S., Blanchard, E. th, Luo, M., Jazwinski, S. M., Taylor, C. M., et al. (2017). Biological Aging and the Human Gut Microbiota. J. Gerontol. A. Biol. Sci. Med. Sci. 72 (11), 1474-1482. doi: 10.1093/gerona/glx042

Mailing LJ, A. J., Buford, T. W., Fields, C. J., and Woods, J. A. (2019). Exercise and the Gut Microbiome: A Review of the Evidence, Potential Mechanisms, and Implications for Human Health. Exerc. Sport Sci. Rev. 47 (2), 75-85. doi: 10.1249/JES.0000000000000183

Malmstrom, T. K., and Morley, J. E. (2013). Frailty and Cognition: Linking Two Common Syndromes in Older Persons. J. Nutr. Health Aging 17 (9), 723-725. doi: 10.1007/s12603-013-0395-y

Marcos-Perez, D., Sánchez-Flores, M., Maseda, A., Lorenzo-López, L., MillánCalenti, J. C., and Gostner, J. M. (2018). Frailty in Older Adults Is Associated With Plasma Concentrations of Inflammatory Mediators But Not With Lymphocyte Subpopulations. Front. Immunol. 9, 1056. doi: 10.3389/ fimmu.2018.01056

Margiotta, E., Miragoli, F., Callegari, M. L., Vettoretti, S., Caldiroli, L., Meneghini, M., et al. (2020). Gut Microbiota Composition and Frailty in Elderly Patients With Chronic Kidney Disease. PloS One 15 (4), e0228530. doi: 10.1371/ journal.pone.0228530

Melzer, D., Pilling, L. C., and Ferrucci, L. (2020). The Genetics of Human Ageing. Nat. Rev. Genet. 21 (2), 88-101. doi: 10.1038/s41576-019-0183-6

Michaudel, C., and Sokol, H. (2020). The Gut Microbiota at the Service of Immunometabolism. Cell Metab. 32 (4), 514-523. doi: 10.1016/ j.cmet.2020.09.004

Mijnarends, D. M., Schols, J. M., Meijers, J. M., Tan, F. E., Verlaan, S., Luiking, Y. C., et al. (2015). Instruments to Assess Sarcopenia and Physical Frailty in Older People Living in a Community (Care) Setting: Similarities and Discrepancies. J. Am. Med. Dir Assoc. 16 (4), 301-308. doi: 10.1016/ j.jamda.2014.11.011

Morais, L. H., Schreiber, H., and Mazmanian, S. K. (2021). The Gut MicrobiotaBrain Axis in Behaviour and Brain Disorders. Nat. Rev. Microbiol. 19 (4), $241-$ 255. doi: 10.1038/s41579-020-00460-0

Morley, J. E., Vellas, B., van Kan, G. A., Anker, S. D., Bauer, J. M., Bernabei, R., et al. (2013). Frailty Consensus: A Call to Action. J. Am. Med. Dir Assoc. 14 (6), 392-397. doi: 10.1016/j.jamda.2013.03.022

Nagpal, R., Mainali, R., Ahmadi, S., Wang, S., Singh, R., Kavanagh, K., et al. (2018). Gut Microbiome and Aging: Physiological and Mechanistic Insights. Nutr. Healthy Aging 4 (4), 267-285. doi: 10.3233/NHA-170030

Nascimento, C. M. C., Zazzetta, M. S., Gomes, G. A. O., Orlandi, F. S., GramaniSay, K., Vasilceac, F. A., et al. (2018). Higher Levels of Tumor Necrosis Factor Beta are Associated With Frailty in Socially Vulnerable Community-Dwelling Older Adults. BMC Geriatr. 18 (1), 268. doi: 10.1186/s12877-018-0961-6

Navarro-Martinez, R., Serrano-Carrascosa, M., Buigues, C., Fernandez-Garrido, J., Sanchez-Martinez, V., Castello-Domenech, A. B., et al. (2019). Frailty Syndrome is Associated With Changes in Peripheral Inflammatory Markers in Prostate Cancer Patients Undergoing Androgen Deprivation Therapy. Urol. Oncol. 37 (12), 976-987. doi: 10.1016/j.urolonc.2019.08.005

O'Toole, P. W., and Jeffery, I. B. (2015). Gut Microbiota and Aging. Science 350 (6265). doi: 10.1126/science.aac8469

Osadchiy, V., Martin, C. R., and Mayer, E. A. (2019). The Gut-Brain Axis and the Microbiome: Mechanisms and Clinical Implications. Clin. Gastroenterol. Hepatol. 17 (2), 322-332. doi: 10.1016/j.cgh.2018.10.002

Palaferri Schieber, A. M., Lee, Y. M., Chang, M. W., Leblanc, M., Collins, B., Downes, M., et al. (2015). Disease Tolerance Mediated by Microbiome E. Coli Involves Inflammasome and IGF-1 Signaling. Science 350 (6260), 558-563.
Parker, B. J., Wearsch, P. A., Veloo, A. C. M., and Rodriguez-Palacios, A. (2020). The Genus Alistipes: Gut Bacteria With Emerging Implications to Inflammation, Cancer, and Mental Health. Front. Immunol. 11, 906. doi: 10.3389/fimmu.2020.00906

Petersen, L. M., Bautista, E. J., Nguyen, H., Hanson, B. M., Chen, L., Lek, S. H., et al. (2017). Community Characteristics of the Gut Microbiomes of Competitive Cyclists. Microbiome 5 (1), 98. doi: 10.1186/s40168-017-0320-4

Picca, A., Ponziani, F. R., and Calvani, R. (2019). Gut Microbial, Inflammatory and Metabolic Signatures in Older People With Physical Frailty and Sarcopenia: Results From the BIOSPHERE Study. Nutrients 12 (1), 65. doi: 10.3390/ nu12010065

Przewlocka, K., Folwarski, M., Kazmierczak-Siedlecka, K., Skonieczna-Zydecka, K., and Kaczor, J. J. (2020). Gut-Muscle AxisExists and May Affect Skeletal Muscle Adaptation to Training. Nutrients 12 (5), 1451. doi: 10.3390/ nu12051451.

Qi, Y., Goel, R., Kim, S., Richards, E. M., Carter, C. S., Pepine, C. J., et al. (2017). Intestinal Permeability Biomarker Zonulin is Elevated in Healthy Aging. J. Am. Med. Dir Assoc. 18 (9), 810.e1-810.e4. doi: 10.1016/j.jamda.2017.05.018

Qu, T., Yang, H., Walston, J. D., Fedarko, N. S., and Leng, S. X. (2009). Upregulated Monocytic Expression of CXC Chemokine Ligand 10 (CXCL10) and Its Relationship With Serum Interleukin-6 Levels in the Syndrome of Frailty. Cytokine 46 (3), 319-324. doi: 10.1016/j.cyto.2009.02.015

Rieu, I., Magne, H., Savary-Auzeloux, I., Averous, J., Bos, C., Peyron, M. A., et al. (2009). Reduction of Low Grade Inflammation Restores Blunting of Postprandial Muscle Anabolism and Limits Sarcopenia in Old Rats. J. Physiol. 587 (Pt 22), 5483-5492. doi: 10.1113/jphysiol.2009.178319

Robertson, D. A., Savva, G. M., Coen, R. F., and Kenny, R. A. (2014). Cognitive Function in the Prefrailty and Frailty Syndrome. J. Am. Geriatr. Soc. 62 (11), 2118-2124. doi: 10.1111/jgs.13111

Robertson, D. A., Savva, G. M., and Kenny, R. A. (2013). Frailty and Cognitive Impairment-a Review of the Evidence and Causal Mechanisms. Ageing Res. Rev. 12 (4), 840-851. doi: 10.1016/j.arr.2013.06.004

Rockwood K, F. R., Stolee, P., Robertson, D., and Beattie, B. L. (1994). Frailty in Elderly People an Evolving Concept. CMAJ 150 (4), 489-495.

Rothhammer, V., Borucki, D. M., Tjon, E. C., Takenaka, M. C., Chao, C. C., Ardura-Fabregat, A., et al. (2018). Microglial Control of Astrocytes in Response to Microbial Metabolites. Nature 557 (7707), 724-728.

Ruan, Q., Yu, Z., Chen, M., Bao, Z., Li, J., and He, W. (2015). Cognitive Frailty, a Novel Target for the Prevention of Elderly Dependency. Ageing Res. Rev. 20, 1 10. doi: 10.1016/j.arr.2014.12.004

Rusanova, I., Diaz-Casado, M. E., Fernandez-Ortiz, M., Aranda-Martinez, P., Guerra-Librero, A., Garcia-Garcia, F. J., et al. (2018). Analysis of Plasma MicroRNAs as Predictors and Biomarkers of Aging and Frailty in Humans. Oxid. Med. Cell Longev. (2018) 7671850. doi: 10.1155/2018/7671850

Sassone-Corsi, M., Nuccio, S. P., Liu, H., Hernandez, D., Vu, C. T., Takahashi, A. A., et al. (2016). Microcins Mediate Competition Among Enterobacteriaceae in the Inflamed Gut. Nature 540 (7632), 280-283.

Scott, K. A., Ida, M., Peterson, V. L., Prenderville, J. A., Moloney, G. M., Izumo, T., et al. (2017). Revisiting Metchnikoff: Age-Related Alterations in Microbiota-Gut-Brain Axis in the Mouse. Brain Behav. Immun. 65, 20-32. doi: 10.1016/j.bbi.2017.02.004

Soysal, P., Stubbs, B., Lucato, P., Luchini, C., Solmi, M., Peluso, R., et al. (2016). Inflammation and Frailty in the Elderly: A Systematic Review and MetaAnalysis. Ageing Res. Rev. 31, 1-8. doi: 10.1016/j.arr.2016.08.006

Stevens, B. R., Goel, R., Seungbum, K., Richards, E., Holbert, M., Pepine, R. C., et al. (2018). Increased Human Intestinal Barrier Permeability Plasma Biomarkers Zonulin and FABP2 Correlated With Plasma LPS and Altered Gut Microbiome in Anxiety or Depression. Gut 67 (8), 1555-1557. doi: 10.1136/gutjnl-2017-314759

Sun, Y., Baptista, L. C., Roberts, L. M., Jumbo-Lucioni, P., McMahon, L. L., Buford, T. W., et al. (2020). The Gut Microbiome as a Therapeutic Target for Cognitive Impairment. J. Gerontol. A. Biol. Sci. Med. Sci. 75 (7), 1242-1250. doi: 10.1093/ gerona/glz281

Tamamouna, V., Panagi, M., Theophanous, A., Demosthenous, M., Michail, M., Papadopoulou, M., et al. (2020). Evidence of Two Types of Balance Between Stem Cell Mitosis and Enterocyte Nucleus Growth in the Drosophila Midgut. Development 147 (11). doi: 10.1242/dev.189472

Tett, A., Huang, K. D., Asnicar, F., Fehlner-Peach, H., Pasolli, E., Karcher, N., et al. (2019). The Prevotella Copri Complex Comprises Four Distinct Clades 
Underrepresented in Westernized Populations. Cell Host Microbe 26 (5), 666679.e7. doi: 10.1016/j.chom.2019.08.018

Thevaranjan, N., Puchta, A., Schulz, C., Naidoo, A., Szamosi, J. C., Verschoor, C. P., et al. (2017). Age-Associated Microbial Dysbiosis Promotes Intestinal Permeability, Systemic Inflammation, and Macrophage Dysfunction. Cell Host Microbe 21 (4), 455-466.e4. doi: 10.1016/j.chom.2017.03.002

Ticinesi, A., Tana, C., Nouvenne, A., Prati, B., Lauretani, F., Meschi, T., et al. (2018). Gut Microbiota, Cognitive Frailty and Dementia in Older Individuals: A Systematic Review. Clin. Interv. Aging 13, 1497-1511. doi: 10.2147/ CIA.S139163

Ticinesi, A., Nouvenne, A., Cerundolo, N., Catania, P., Prati, B., and Tana, C. (2019). Muscle Mass and Function in Aging: A Focus on Physical Frailty and Sarcopenia. Nutrients 11 (7). doi: 10.3390/nu11071633

Tilg, H., Zmora, N., Adolph, T., and Elinav, E. (2020). The Intestinal Microbiota Fuelling Metabolic Inflammation. Nat. Rev. Immunol. 20 (1), 40-54. doi: 10.1038/s41577-019-0198-4

Valdes-Ramos, R., Martinez-Carrillo, B. E., Aranda Gonzalez, I. I., Guadarrama, A. L., Pardo-Morales, R. V., Tlatempa, P., et al. (2010). Diet, Exercise and Gut Mucosal Immunity. Proc. Nutr. Soc. 69 (4), 644-650. doi: 10.1017/ S0029665110002533

van Tongeren, S. P., Slaets, J., Harmsen, P., and Welling, H. (2005). Fecal Microbiota Composition and Frailty. Appl. Environ. Microbiol. 71 (10), 6438-6442. doi: 10.1128/AEM.71.10.6438-6442.2005

Walston, J. D., Fedarko, N., Yang, H., Leng, S., Beamer, B., and Espinoza, S. (2015). Connecting Age-Related Biological Decline to Frailty and Late-Life Vulnerability. Nestle Nutr. Inst. Workshop Ser. 83, 1-10. doi: 10.1159/000382052

Walston, J., Fedarko, N., and Yang, H. (2008). The Physical and Biological Characterization of a Frail Mouse Model. J. Gerontol. A. Biol. Sci. Med. Sci. 63 (4), 391-398. doi: 10.1093/gerona/63.4.391

Wang, X., Sun, G., Feng, T., Zhang, J., Huang, X., Wang, T., et al. (2019). Sodium Oligomannate Therapeutically Remodels Gut Microbiota and Suppresses Gut Bacterial Amino Acids-Shaped Neuroinflammation to Inhibit Alzheimer's Disease Progression. Cell Res. 29 (10), 787-803. doi: 10.1038/s41422-0190216-x

Wang, Z., Usyk, M., Sollecito, C. C., Qiu, Y., Williams-Nguyen, J., Hua, S., et al. (2020). Altered Gut Microbiota and Host Metabolite Profiles in Women With Human Immunodeficiency Virus. Clin. Infect. Dis. 71 (9), 2345-2353. doi: $10.1093 / \mathrm{cid} / \mathrm{ciz} 1117$

Waters, J. L., and Ley, R. E. (2019). The Human Gut Bacteria Christensenellaceae are Widespread, Heritable, and Associated With Health. BMC Biol. 17 (1), 83. doi: 10.1186/s12915-019-0699-4

Wilson, D., Jackson, T., Sapey, E., and Lord, J. M. (2017). Frailty and Sarcopenia: The Potential Role of an Aged Immune System. Ageing Res. Rev. 36, 1-10. doi: 10.1016/j.arr.2017.01.006

Woerther, P. L., Antoun, S., Chachaty, E., and Merad, M. (2017). Eggerthella Lenta Bacteremia in Solid Tumor Cancer Patients: Pathogen or Witness of Frailty? Anaerobe 47, 70-72. doi: 10.1016/j.anaerobe.2017.04.010

Wu, S. C., Cao, Z. S., Chang, K. M., and Juang, J. L. (2017). Intestinal Microbial Dysbiosis Aggravates the Progression of Alzheimer's Disease in Drosophila. Nat. Commun. 8 (1), 24.
Wu, C. S., Wei, Q., Wang, H., Kim, D. M., Balderas, M., Wu, G., et al. (2020). Protective Effects of Ghrelin on Fasting-Induced Muscle Atrophy in Aging Mice. J. Gerontol. A. Biol. Sci. Med. Sci. 75 (4), 621-630. doi: 10.1093/gerona/ gly256

Wu L, Z. T., Zinellu, A., Rubino, S., Kelvin, D. J., and Carru, C. (2019). A CrossSectional Study of Compositional and Functional Profiles of Gut Microbiota in Sardinian Centenarians. mSystems 4 (4), e00325-e00319. doi: 10.1128/ mSystems.00325-19

Xia, Z., Cholewa, J., Zhao, Y., Shang, H. Y., Yang, Y. Q., Araújo Pessôa, K., et al. (2017). Targeting Inflammation and Downstream Protein Metabolism in Sarcopenia: A Brief Up-Dated Description of Concurrent Exercise and Leucine-Based Multimodal Intervention. Front. Physiol. 8, 434. doi: 10.3389/ fphys.2017.00434

Yan, J., Herzog, J. W., Tsang, K., Brennan, C. A., Bower, M. A. , Garrett, W. S., et al. (2016). Gut Microbiota Induce IGF-1 and Promote Bone Formation and Growth. Proc. Natl. Acad. Sci. U. S. A. 113 (47), E7554-e7563. doi: 10.1073/ pnas. 1607235113

Yang, Y., Hao, Q., Flaherty, J., Cao, L., Zhou, J., Su, L., et al. (2018). Comparison of Procalcitonin, a Potentially New Inflammatory Biomarker of Frailty, to Interleukin-6 and C-reactive Protein Among Older Chinese Hospitalized Patients. Aging Clin. Exp. Res. 30 (12), 1459-1464. doi: 10.1007/s40520-0180964-3

Yang, X., Yu, D., Xue, L., Li, H., and Du, J. (2020). Probiotics Modulate the Microbiota-Gut-Brain Axis and Improve Memory Deficits in Aged SAMP8 Mice. Acta Pharm. Sin. B. 10 (3), 475-487. doi: 10.1016/j.apsb.2019.07.001

Zhang, L., Wang, Y., Xiayu, X., Shi, C., Chen, W., Song, N., et al. (2017). Altered Gut Microbiota in a Mouse Model of Alzheimer's Disease. J. Alzheimers Dis. 60 (4), 1241-1257. doi: 10.3233/JAD-170020

Zhang, T., Li, Q., Cheng, L., Buch, H., and Zhang, F. (2019). Akkermansia Muciniphila is a Promising Probiotic. Microb. Biotechnol. 12 (6), 1109-1125. doi: 10.1111/1751-7915.13410

Zhang, L., Liao, J., Chen, Q., Chen, M., Kuang, Y., Chen, L., et al. (2020). Characterization of the Gut Microbiota in Frail Elderly Patients. Aging Clin. Exp. Res. 32 (10), 2001-2011. doi: 10.1007/s40520-019-01385-2

Zhao, L. (2010). Genomics: The Tale of Our Other Genome. Nature 465 (7300), 879-880. doi: $10.1038 / 465879$ a

Zhou, J., and Boutros, M. (2020). JNK-Dependent Intestinal Barrier Failure Disrupts Host-Microbe Homeostasis During Tumorigenesis. Proc. Natl. Acad. Sci. U. S. A. 117 (17), 9401-9412. doi: 10.1073/pnas.1913976117

Conflict of Interest: The authors declare that the research was conducted in the absence of any commercial or financial relationships that could be construed as a potential conflict of interest.

Copyright $\odot 2021 \mathrm{Xu}, \mathrm{Liu}, \mathrm{Liu}, \mathrm{Chen}$, Wang, Jiang and Xiong. This is an open-access article distributed under the terms of the Creative Commons Attribution License (CC BY). The use, distribution or reproduction in other forums is permitted, provided the original author(s) and the copyright owner(s) are credited and that the original publication in this journal is cited, in accordance with accepted academic practice. No use, distribution or reproduction is permitted which does not comply with these terms. 